\title{
Single-stage debridement via autogenous iliac bone graft through the OLIF corridor and lateral fixation in treating spontaneous single-level lumbar pyogenic spondylodiscitis
}

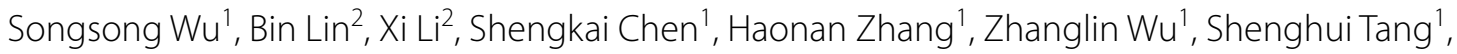
Yuehua Yang ${ }^{1}$ and Biru Liang ${ }^{1 *}$

\begin{abstract}
Background: The aim of the present study was to investigate the efficacy and safety of mini-open oblique debridement and lumbar interbody fusion combined with lateral screw fixation for treating single-level pyogenic spondylodiscitis.
\end{abstract}

Methods: Twelve patients with single-level lumbar pyogenic spondylodiscitis underwent OLIF combined with lateral screw fixation were analyzed. Patients underwent follow-up for 12 to 24 months. The clinical characteristics, etiological examinations, operative time, intraoperative blood loss, Oswestry Disability Index (ODI), visual analog scale score (VAS), postoperative complications, and the bony fusion rate were recorded.

Results: The mean follow-up period of time was 14.8 months. The average operative time and intra-operative blood loss were $129.0 \pm 19.76 \mathrm{~min}$ and $309.2 \pm 92.96 \mathrm{~mL}$, respectively. No severe intra-operative complications were observed during surgery, except in 1 case that develops abdominal pain and distension after surgery, 2 cases that develop left-sided transient thigh pain/numbness and 8 cases that complains of donor site (iliac crest) pain. All of these symptoms disappeared 8 weeks after surgery. Tissue sample cultures were obtained from all patients intraoperatively and four (33.3\%) were positive, including 2 with Staphylococcus aureus, 1 with Staphylococcus epidermidis, and 1 with Escherichia coli. During an average of 22.5 \pm 2.1 days (range, 14-29 days) after surgery, WBC, CPR, and ESR levels in all patients had returned to normal. All patients were pain free with no recurring infection. Solid bony fusions were observed in all cases within 6 months, including 10 with I grade fusion, 2 with II grade fusion according to the classification suggested by Burkus et al. No fixation failure was observed during follow up and solid bony fusions were observed in all 12 patients at finally follow-up. A significant postoperative increase was also observed in the mean segmental height and lordosis $(P<0.05)$, followed by a slight decrease of segmental height and lordosis at final follow-up. At the final follow up, the mean VAS (1.5 \pm 0.6$)$ and ODI (18.9 \pm 7.6$)$ were significantly lower than VAS $(8.4 \pm 2.7)$ and $\mathrm{ODI}(71.2 \pm 16.5)$ before surgery $(P<0.01)$.

\footnotetext{
*Correspondence: 13003937167@163.com

1 Department of Orthopaedics, the Fifth Affiliated Hospital, Southern

Medical University, No. 566 Congcheng Avenue, Conghua District,

Guangzhou 510900, People's Republic of China

Full list of author information is available at the end of the article
}

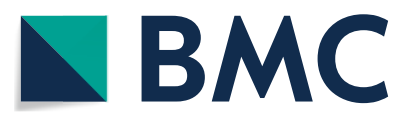

(c) The Author(s) 2021. Open Access This article is licensed under a Creative Commons Attribution 4.0 International License, which permits use, sharing, adaptation, distribution and reproduction in any medium or format, as long as you give appropriate credit to the original author(s) and the source, provide a link to the Creative Commons licence, and indicate if changes were made. The images or other third party material in this article are included in the article's Creative Commons licence, unless indicated otherwise in a credit line to the material. If material is not included in the article's Creative Commons licence and your intended use is not permitted by statutory regulation or exceeds the permitted use, you will need to obtain permission directly from the copyright holder. To view a copy of this licence, visit http://creativecommons.org/licenses/by/4.0/. The Creative Commons Public Domain Dedication waiver (http://creativeco mmons.org/publicdomain/zero/1.0/) applies to the data made available in this article, unless otherwise stated in a credit line to the data. 
Conclusion: Single-stage debridement with autogenous iliac bone graft through the OLIF corridor and lateral fixation was a feasible surgical approach in our consecutive 12 cases of pyogenic spondylitis.

Keywords: Lumbar spondylodiscitis, Oblique lateral interbody fusion, Minimally invasive

\section{Introduction}

The overall incidence of spondylodiscitis is approximately $2.2 / 100,000$ per year $[1,2]$ and accounts for only $2-7 \%$ of all osteomyelitis [3]. Although Spondylodiscitis can affect patients of any age and most commonly occurs in adults (male vs female, 2:1). Especially, the high risk factors was susceptibility to spondylodiscitis including: aged $>50$ years, diabetes mellitus, intravenous drug abusers and chronic kidney or liver disease.

The most frequently involved spinal segment is the lumbar spine (58\%), followed by the thoracic spine (30\%), and the cervical spine (11\%) [4]. Spondylodiscitis commonly results from primary hematogenous infection and is associated with destruction of the intervertebral disc, adjacent end-plates and vertebral body. Typically, pathogens of spondylodiscitis is caused by Staphylococcus species, Escherichia coli, and Mycobacterium tuberculosis. Typically, conservative treatment is used for most patients with pyogenic spondylodiscitis [5]. However, spondylodiscitis is difficult to treat because the positive rate of the causative organisms in spine is low. It is reported that $10-60 \%$ positive rate were obtained by fine-needle aspiration [5-7]. Ineffective conservative treatment may further worsen symptom and lead to serious complications, including epidural abscess, spinal kyphosis deformity, compression of nerves or neurological deficit symptoms $[8,9]$. Therefore, surgery followed by treatment with antibiotics is required when conservative treatment fails [10]. It allows for effective debridement and rapid cure of inflammation.

However, the best surgical approach remains controversial. An anterior only approach debridement, a posterior only approach debridement, and a combined anterior-posterior debridement have been reported $[11,12]$. However, the anterior lumbar interbody fusion (ALIF) has the potential risk for visceral and vascular injury, while posterior approach damages posterior structure and led instability of the spine [13-15]. Furthermore, the extreme lateral lumbar interbody fusion (XLIF) approach is associated with lumbar plexus injury risk [16, 17]. In addition, percutaneous endoscopic lavage and drainage is reported as an effective minimal invasive method for the treatment of the earlystage spinal infection patients. Obviously, this surgery is not suitable for patients with neurological deficit and mechanical instability [18-20].
Oblique lateral interbody fusion (OLIF), an approach accesses the spine between the abdominal anterior vessel and the psoas muscle [3], is considered the solution to the limitations of ALIF, XLIF and posterior lumbar interbody fusion (PLIF) [21]. Moreover, a previous research reported that OLIF in combination with posterior internal fixation was effective and safe for single-level spontaneous lumbar pyogenic spondylodiscitis [3]. However, it has never been reported as OLIF combined with lateral screw fixation for lumbar pyogenic spondylodiscitis.

In the present study, we retrospectively reviewed 12 cases of single-level spontaneous lumbar pyogenic spondylodiscitis that were treated in our hospital from December 2014 to December 2018 using the OLIF combined with lateral screw fixation. The aim of this study is to investigate the efficiency and safety of the OLIF combined with lateral screw fixation in treating pyogenic spondylodiscitis.

\section{Materials and methods}

\section{Inclusion and exclusion criteria}

Twelve consecutive patients (male 8 cases, female 4 cases) suffering from lumbar spondylodiscitis were enrolled. Lumbar pyogenic spondylodiscitis was confirmed in these patients on the basis of the following: back pain or leg pain accompanied by fever; Laboratory results including a culture study, erythrocyte sediment rate (ESR), white blood cells (WBC), and C-reactive protein (CRP), and the results of X-rays, CT scans, and MRI. These results were also confirmed by histopathological examination regardless of the bacteriological culture results [3]. The severity of spondylodiscitis was classified by Pee et al. [22] Grade I represents isolated discitis with minor destruction of vertebral endplates, Grade II represents discitis with moderate endplate destruction (including a portion of the vertebral body), and Grade III represents discitis with destruction of the vertebral body. All patients were included by the following inclusion and exclusion criteria.

\section{Inclusion criteria were as follows:}

(I)Diagnosis of single-segment pyogenic spondylodiscitis within the T12 to L5 areas;

(II)Persistent symptom and signs: infection, persistent pain, deterioration of neurological symptoms; progression, persistence, or recurrence of the disease failed to 6-week conservative treatment; 

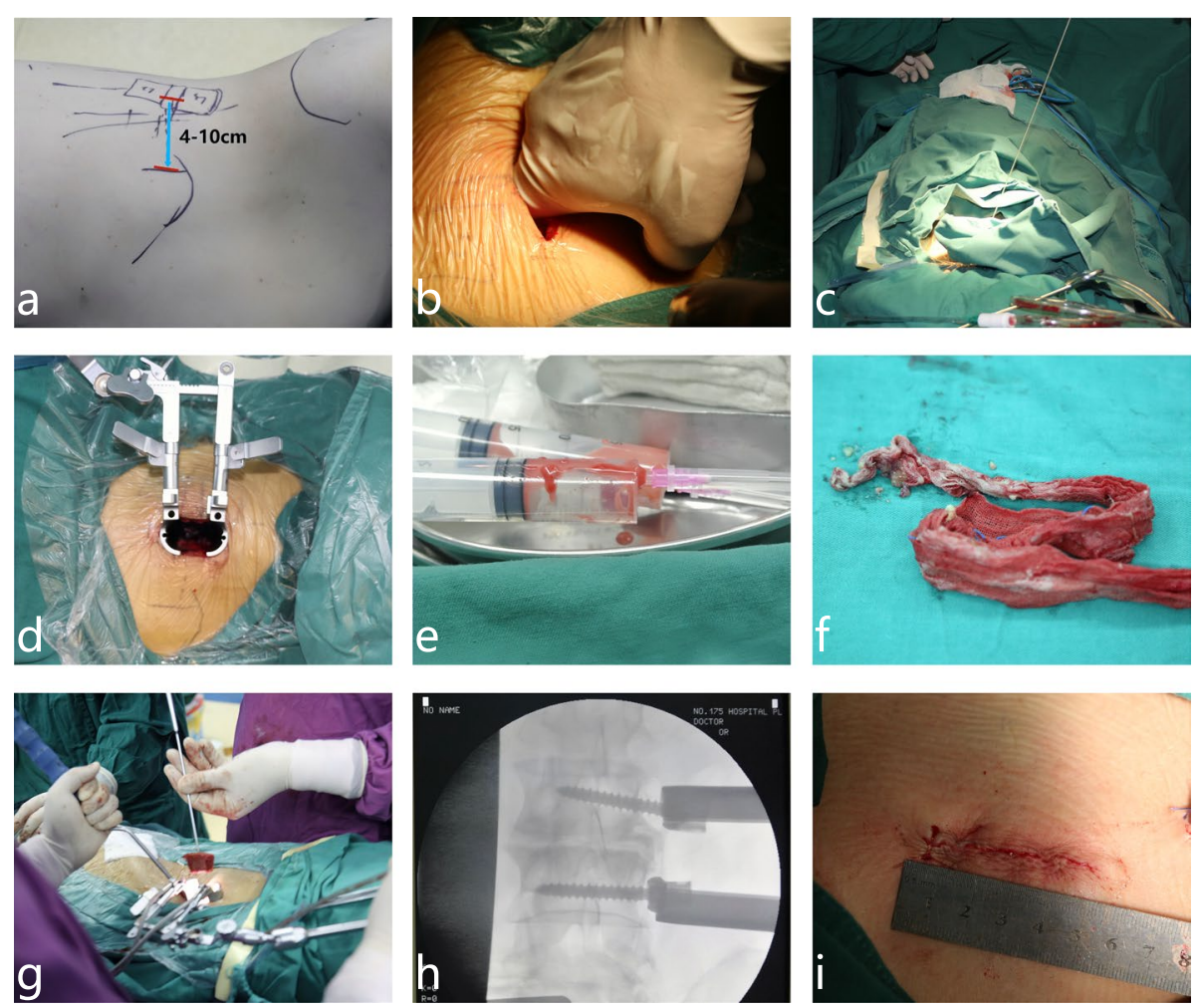

Fig. 1 Steps of the OLIF combined with lateral fixation for lumbar spondylodiscitis. a Patient positioning and skin marking. b Blunt muscle dissection. $\mathbf{c}$ Placement of initial probe. $\mathbf{d}$ Dilation and retractor placement. e Bacterial culture of pyogenic fluids. $\mathbf{f}$ Clearing the focus completely with gauze. $\mathbf{g}$ lliac bone grafting. $\mathbf{h}$ Lateral screw placement. i Wound closure

(III)Spontaneous pyogenic spondylodiscitis with no apparent cause;

(IV)Surgically treated using one-stage debridement, interbody fusion with autogenous iliac bone graft through the OLIF approach combined with lateral screw fixation.

(V)A minimal follow-up time beyond 12 months;

\section{Exclusion criteria were as follows:}

(i) Infection diagnosed as tuberculosis;

(ii) Secondary pyogenic spondylodiscitis;

(iii) Treatment with other approaches; or patients with posterior pathology requiring decompression and posterior fusion.

\section{Operative approach}

\section{Pre-surgery preparation}

All patients were treated with conservative therapy including immobilization and administration of empirical broad-spectrum antibiotics for a minimum of 2 weeks. Each patient's ESR, CRP, WBC levels were measured. All patients were evaluated with plain radiographs (X-rays), computed tomography (CT), and magnetic resonance imaging (MRI). The position of the psoas, anterior vasculature, posterior nerve structures and the kidneys was evaluated by CT and MRI.

\section{Anesthesia and surgical position}

All patients were continuously monitored during surgery using general anesthesia and each patient was positioned right lateral decubitus on a radiolucent table. The legs were only slightly flexed in order to prevent the patient from rolling on the bed. X-rays was used to confirm the target segment and mark the location for the initial incision.

\section{Oblique approach and exposure}

A $4-10 \mathrm{~cm}$ oblique incision parallel to the fiber of the external oblique abdominal muscle incision was made in the target spinal segment (Fig. 1a). Three muscular layers of the external oblique, the intra-abdominal oblique, and the transverse abdominis muscles were bluntly dissected and the retroperitoneal space was directly exposed by fingers of surgeon (Fig. 1b). Subsequently, a probe is guided down to the disc (Fig. 1c). The guidewire is placed through this probe and sequential dilation was performed 
to displace the surrounding tissues. A retractor is placed over the dilators (Fig. 1d).

\section{Debridement and reconstruction}

Then infectious lesions, sequestra, and all infected discs and endplate were meticulously debrided and cleared by syringe (Fig. 1e), followed by precise curettage to the healthy boundary (Fig. 1f). An appropriate autologous bone graft derived from the iliac crest was punched into the defect to reconstruct the anterior column after debridement, followed by lateral screw fixation was performed (Fig. 1g). The screws were placed on the adjacent vertebral body if the infected lesion exceeded $50 \%$ of the vertebrae and the screw was placed on the infected vertebral body if lesion less than $50 \%$. X-ray examination was taken to confirm the appropriate internal fixation and the appropriate position of autologous bone graft (Fig. 1h). Finally, the drainage tube was put into the cavity and the incision was closed (Fig. 1i).

\section{Post-surgery treatment}

After the surgery, all patients were placed on strict bed rest for 7 days and ambulated with an assistive brace after 7 days. Tissue sample cultures were obtained from all patients intraoperatively and four (33.3\%) were positive. Intravenous antibiotic therapy was continuously administered for a minimum of 6 weeks postoperatively based on the specific microbial sensitivities and the identified pathogenic organism. Oral antibiotics were not routinely used after discharge. A full course of broad-spectrum antibiotics was also administered for the patient with negative culture results.

\section{Outcome measurements}

The characteristics of patients, peri-operative laboratory, intra-operative blood loss and peri-operative complications were recorded. WBC, CRP, and ESR levels were assessed weekly after surgery until the results returned to normal. Clinical outcomes were evaluated using visual analog scale (VAS) score and oswestry disability index (ODI) score. The visual analogue scale (VAS) scoring system was used to evaluate pain level of patients from 0 (no pain) to 10 (very intense pain). The Oswestry disability index (ODI) is one of the most commonly used condition-specific outcome measures for spinal disorders. It includes 10 sections: walking, sitting, standing, pain intensity, sex life, social life, personal care, lifting, sleeping and traveling. All patients underwent X-rays, $\mathrm{CT}$, and MRI of the lumbar spine before and after surgery. Specially, the bone graft healing, the segmental lordosis and height were assessed by $\mathrm{X}$ rays. $\mathrm{X}$ rays of the lumbar spine 1 day after surgery and again 1, 3, 6 and 12 months after surgery. The extent of bone graft healing was analyzed by the classification suggested by Burkus et al. [23] Grade I (definitely solid) - no motion on flexion-extension radiographs, continuous bony bridge, new bone formation adjacent on CT scan; Grade II (possibly solid) - no motion on dynamic radiographs, continuous bony incorporation, without evidence of new bone formation adjacent; Grade III (probably not solid) - no motion excluding evidence of bony incorporation; and Grade IV (definitely not solid) - motion on dynamic radiographs with no evidence of bony bridge. The absence of infection was defined as having no fever, pain, or graft bone union at the interface 12 months after surgery $[24,25]$.

\section{Statistical analysis}

All data were presented as mean \pm standard error of mean (SEM). Datas were analyzed by Student t test using the SPSS19.0 program (SPSS Inc., Chicago, IL, USA) and a $p$ value $<0.05$ was considered statistically significant.

\section{Results \\ Demographic data}

A total of 12 cases ( 8 males and 4 female) were included according the inclusion and exclusion criteria. The average age was 56.5 years (range, $35-73$ years), with a minimum follow-up duration of 12 months (mean, 14.8 mo; range $12-24$ months). The mean duration of surgery was $129.0 \pm 19.76 \mathrm{~min}$. The mean blood volume loss during surgery was $309.2 \pm 92.96 \mathrm{ml}$. During an average of $22.5 \pm 2.1$ days (range, 14-29 d) after surgery, WBC, CPR, and ESR levels in all patients had returned to normal. 3 cases complained of preoperative neurological defects preoperatively (Frankel Grade D) and all of them recovered to Frankel Grade E at 3-month follow-up. Tissue sample cultures were obtained from all patients intraoperatively and four (33.3\%) were positive, including 2 with Staphylococcus aureus, 1 with Staphylococcus epidermidis, and 1 with Escherichia coli. A summary of the demographic data and surgical parameters are summarized in Table 1.

\section{Clinical outcome}

All patients were back and radicular pain free at finally follow-up. The mean preoperative, 1-month postoperative, and final follow-up VAS scores were $8.4 \pm 2.7$, $2.0 \pm 0.5$ and $1.5 \pm 0.6$ respectively. The mean preoperative, 1-month postoperative, and final follow-up ODI scores were $71.2 \pm 16.5,32.5 \pm 8.1$, and $18.9 \pm 7.6$ respectively. These follow-up VAS and ODI scores showed statistical significances compared with preoperative values (independent $\mathrm{t}$ test, $P<0.01$ ) (Table 2). 
Table 1 Demographic data and surgical parameters of 12 patients

\begin{tabular}{|c|c|c|c|c|c|c|c|c|}
\hline Case & Sex/Age & Disease level & $\begin{array}{l}\text { Grade of } \\
\text { infection }\end{array}$ & Surgery (min) & Blood Loss (mL) & Causative Organism & $\begin{array}{l}\text { Frankel score } \\
\text { (Pre/Post op) }\end{array}$ & $\begin{array}{l}\text { Follow-up } \\
\text { time } \\
\text { (months) }\end{array}$ \\
\hline 1 & $M / 49$ & L3-4 & $\|$ & 110 & 240 & - & $E / E$ & 12 \\
\hline 2 & $M / 65$ & L2-3 & III & 96 & 230 & Staphylococcus aureus & $E / E$ & 15 \\
\hline 3 & $\mathrm{~F} / 62$ & L3-4 & $\|$ & 125 & 300 & - & $\mathrm{D} / \mathrm{E}$ & 18 \\
\hline 4 & $M / 59$ & L3-4 & । & 120 & 290 & - & $E / E$ & 24 \\
\hline 5 & $M / 73$ & $\llcorner 4-5$ & III & 135 & 250 & Escherichia coli & $E / E$ & 12 \\
\hline 6 & $M / 41$ & L2-3 & III & 164 & 550 & Staphylococcus epidermidis & $\mathrm{D} / \mathrm{E}$ & 15 \\
\hline 7 & $F / 55$ & $\mathrm{~L} 1-2$ & $\|$ & 150 & 370 & - & $E / E$ & 18 \\
\hline 8 & $F / 38$ & L3-4 & $\|$ & 148 & 310 & Staphylococcus aureus & $\mathrm{D} / \mathrm{E}$ & 15 \\
\hline 9 & M/35 & L2-3 & III & 137 & 420 & - & $E / E$ & 12 \\
\hline 10 & $M / 71$ & L3-4 & III & 144 & 300 & - & $E / E$ & 12 \\
\hline 11 & $F / 63$ & L3-4 & I & 106 & 210 & - & $E / E$ & 12 \\
\hline 12 & $M / 67$ & $\llcorner 4-5$ & $\|$ & 113 & 240 & - & $E / E$ & 12 \\
\hline Average & $56.5 \pm 12.41$ & - & - & $129.0 \pm 19.76$ & $309.2 \pm 92.96$ & - & - & $14.8 \pm 3.56$ \\
\hline
\end{tabular}

Table 2 VAS scores and ODI scores

\begin{tabular}{lllll}
\hline Item & Pre-op & 1 mo Post-op & 3mo Post-op & Final follow-up \\
\hline VAS & $8.4 \pm 2.7$ & $2.0 \pm 0.5$ & $1.8 \pm 0.5$ & $1.5 \pm 0.6$ \\
ODI & $71.2 \pm 16.5$ & $32.5 \pm 8.1$ & $21.2 \pm 8.4$ & $18.9 \pm 7.6$ \\
\hline
\end{tabular}

\section{Imaging measurements}

No internal fixation failure was observed in the X-ray or CT during follow up (a case is shown in Fig. 2). According to the classification suggested by Burkus et al [23], 10 cases showed grade I fusion status, which was assessed with $\mathrm{CT}$ and flexion-extension radiographs at 6 months postoperatively follow-up. 2 case showed grade II fusion status. Neither of them complained of any clinical symptoms related to pseudoarthrosis and solid bony fusions were observed in all 12 patients at 12 months postoperatively follow-up. As shown in Table 3, a significantly postoperative increase was also observed in the mean segmental height and lordosis $(P<0.05)$, followed by a slight decrease of segmental height $(P<0.05)$ and lordosis at final follow-up (Measurement is shown in Fig. 3). However, there was also a significant difference in segmental lordosis and height at final follow-up, as compared with that in preoperative group. The data suggested that restoration of segmental lordosis and height were successfully achieved by the surgery and maintained at final follow-up.

\section{Complication}

No incision infection, ureter injury, retrograde ejaculation, spinal nerve injury, major vessel injury, urinary injury or hardware failure were observed during surgery. only $1(8.3 \%)$ case developed abdominal pain and distension after surgery, which was effectively relieved after fasting and laxative measures for 3 days. 2 cases (16.6\%) developed left-sided transient thigh pain/numbness and the symptom diminishes after 2 weeks of surgery. 8 cases complained of donor site (iliac crest) pain but all of them relieve after 8 weeks of surgery. In addition, no infections had recurred.

\section{Discussion}

For most patients with pyogenic spondylodiscitis, conservative therapy is an effective economical and safe treatment $[5,26,27]$, but surgical intervention is required when it develops epidural abscess, spinal kyphosis deformity, compression of nerves or neurological deficit symptoms $[8,9]$. The purpose of surgical treatment for spondylodiscitis is to debride the lesion, decompress the nerve, relieve the symptoms, correct the spinal deformity, and reconstruct spinal stability. In this study, causative organisms were identified in 4 patients $(33.3 \%)$, which was comparable to previous reports that the pathogen could be detected in 30 to $83 \%$ of cases [27]. The implantation of osteosynthesis material in an infected wound area is controversy because it may increase the risk of metal surface microbial colonization and lead to persistent infection. However, recent studies demonstrated that bone grafting followed internal fixation could improve spine stability, promote bone fusion, but did not increased rate of infection [10, 12, 27, 28]. Therefore, debridement following bone grafting and internal fixation is the current standard surgical protocol for treatment of spondylodiscitis. However, controversy remains over whether internal fixation should be done in a single 

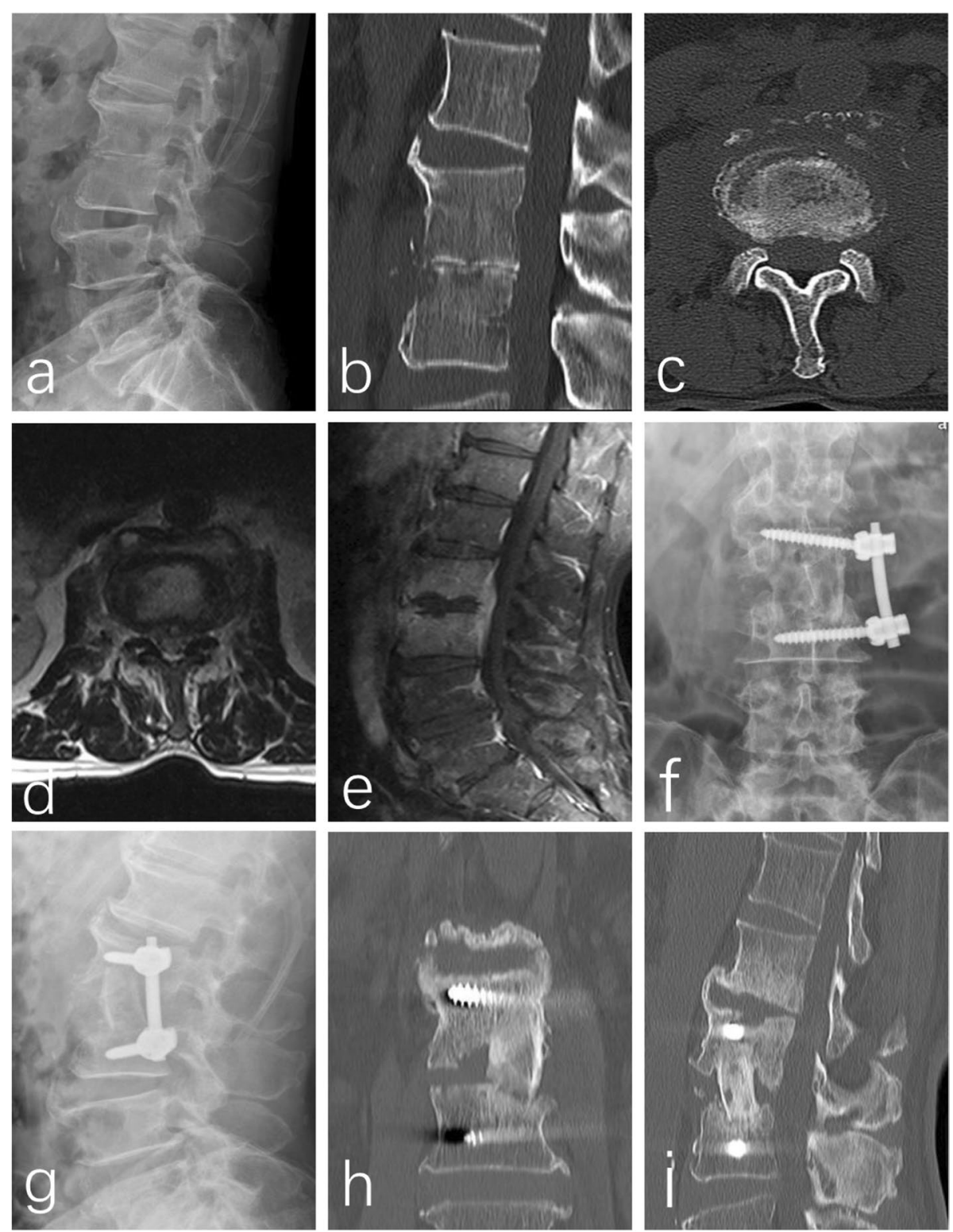

Fig. 2 Sixty-five-year-old male with lumbar spondylodiscitis of $L_{2-3}$. a Pre-op $X$-ray demonstrating disc space narrowing at $L_{2-3}$. b, $\mathbf{c}$ Pre-op $C T$ demonstrating bone destruction. d, e Pre-op MRI demonstrating abnormal signal, soft tissue swelling, and spinal cord compressed. $\mathbf{f}, \mathbf{g}$ CT at 3 days after operation demonstrating Segmental lordosis and height was restored. $\mathbf{h}, \mathbf{i} C T$ at 6 months follow-up demonstrating bony fusion

stage or in two stages after debridement, the choice of surgical approach and internal fixation.

Spinal infection is usually involved in vertebral bodies and discs, so anterior approach is often recommended to debride the lesion, reconstruct spinal stability and achieve better clinical results [12]. Several researchers

Table 3 Changes in segmental lordosis and height

\begin{tabular}{llll}
\hline Item & Pre-op & Post-op & Final follow-up \\
\hline segmental lordosis & $1.5 \pm 4.1^{\circ}$ & $8.5 \pm 5.6^{\circ}$ & $5.3 \pm 4.7^{\circ}$ \\
segmental height & $62.3 \pm 9.3 \mathrm{~mm}$ & $70.6 \pm 10.4 \mathrm{~mm}$ & $66.5 \pm 9.7 \mathrm{~mm}$ \\
\hline
\end{tabular}

reported that ALIF or XLIF corridor followed by a posterior stabilization procedure is also an option for spondylodiscitis $[11,14]$. However, these ALIF or XLIF debriding approaches have certain risks, including major vascular injuries, the psoas major muscle and lumbar plexus injuries, urinary retention, constipation, and pain/ numbness in the thigh $[11,14,16]$.

OLIF approach was first reported by Mayer and applied to lumbar disc disease through the natural space between the lateral border of the abdominal vessel and the psoas muscle [29]. In this study, no severe nerve or vascular 


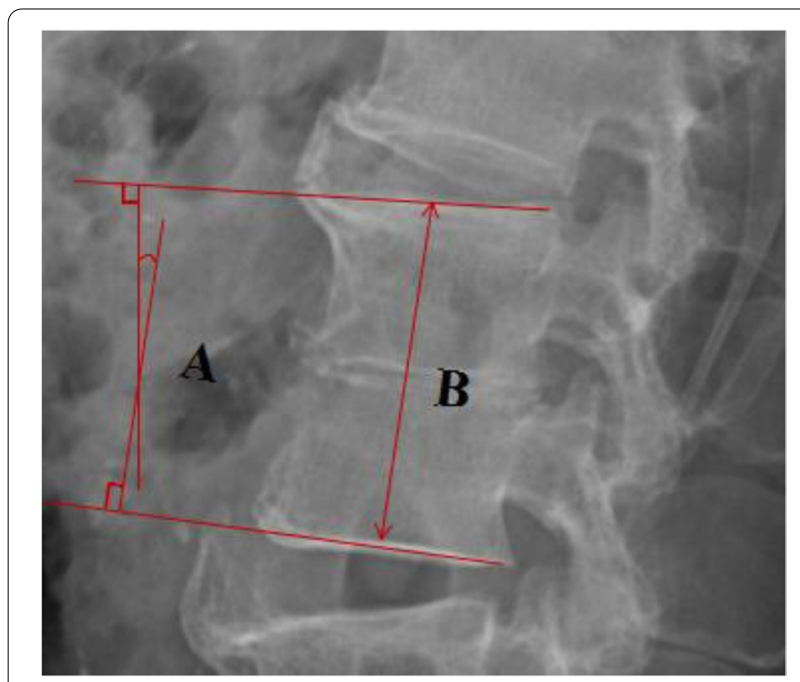

Fig. 3 Measurement of segmental lordosis (A) and height (B). A: The lordotic angle was measured by the angle of perpendicular lines from the upper and lower endplates. B: The segmental height was measured as the midpoint distance from the endplates injuries were observed during and after surgery, which suggested that the OLIF was a safe approach. only 1 case developed abdominal pain and distension after surgery, which was effectively relieved after fasting and laxative measures for 3 days. 2 cases (16.6\%) developed left-sided transient thigh pain/numbness and the symptom diminished 2 weeks after surgery. Consistently, it is reported that the incidence of transient thigh pain/numbness occurred in $8.3-20.4 \%$ and permanent thigh pain/numbness occurred in $4-5 \%$ in these cases treated with OLIF [30-33]. Thus, the bone grafts in all patients were fused within 12 months after surgery, which was comparable to the results presented in previous reports [34,35].

Segmental lordosis and height were restored satisfactory at the immediate postoperative period in all 12 cases, because the OLIF approach allows for wider exposure of the disc space and the size of the debridement area can be directly measured to fill in the defect and better stabilize the anterior column. It maintains the segmental lordosis and height although a slight decrease were observed at final follow-up, suggesting that it is an effective anterior grafting with autologous bone strut. In our study, 8 cases complained of donor site (iliac crest) pain. To reduce this complication, researchers suggest that cages instead of autologous bone may be a viable option for single-stage anterior reconstruction [22, 36, 37]. However, it is notable that the high incidence cage subsidence (range from 10 to $13.6 \%$ ) were reported [28, 37, 38]. Furthermore, cages instead of autologous bone may lead to a higher medical burden for these patients. In addition, VAS and ODI scores at 12 months after surgery had significantly improved over those before surgery, which is comparable to the results presented in a previous report treated with OLIF combined with posterior pedicle screws [3]. However, OLIF corridor combined with lateral screw theoretically avoid additional iatrogenic injury to the posterior structures.

\section{Conclusion}

Single-stage debridement with autogenous iliac bone graft through the OLIF corridor and lateral fixation is an effective and safe surgical approach in our consecutive 12 cases of pyogenic spondylitis.. However, further studies with longer follow-up and more patients are still needed.

\section{Abbreviations \\ OLIF: Oblique lateral interbody fusion; ODI: Oswestry Disability Index; VAS: Visual analog scale score; WBC: White blood cell; CPR: C-reactive protein; ESR: Erythrocyte sedimentation rate; ALIF: Anterior lumbar interbody fusion; XLIF: Extreme lateral lumbar interbody fusion; PLIF: Posterior lumbar interbody fusion; CT: Computed tomography; MRI: Magnetic resonance imaging; SEM: Standard error of mean.}

\section{Acknowledgments}

We would like to thank the editors, reviewers and other persons for their assistance to improve the manuscript.

\section{Authors' contributions}

SS W and B L put forward the concept of this study and designed this experiment, $B R L$ and $Y H Y$ revised this manuscript. $X L, S K C, H N Z, Z L W$ and $S H$ $T$ collected data and performed the statistical analysis. All authors read and approved the final manuscript.

\section{Funding}

This work was supported by the National Natural Science Foundation of China [grant numbers: 81501196].

\section{Availability of data and materials}

The data that support the findings of this study are available from the corresponding authors but restrictions apply to the availability of these data, which were used under license for the current study, and so are not publicly available. Data are however available from the authors upon reasonable request and with permission of the hospital ethical institutional review board.

\section{Declarations}

Ethics approval and consent to participate

This study was approved by the Ethics Committee of the Fifth Affiliated Hospital of Southern Medical University. All procedures performed in studies involving human participants were in accordance with the ethical standards of the institutional standards. Written informed consents were obtained from all individual participants included in the study.

\section{Consent for publication}

Informed consent was obtained from all individual participants included in the study.

\section{Competing interests}

The authors declare that they have no conflict of interest.

\section{Author details}

${ }^{1}$ Department of Orthopaedics, the Fifth Affiliated Hospital, Southern Medical University, No. 566 Congcheng Avenue, Conghua District, Guangzhou 510900, People's Republic of China. ${ }^{2}$ Department of Orthopaedics, the Affiliated 
Southeast Hospital of Xiamen University, Zhangzhou 363000, People's Republic of China.

Received: 31 March 2021 Accepted: 25 October 2021

Published online: 15 November 2021

\section{References}

1. Tsantes AG, Papadopoulos DV, Vrioni G, et al. Spinal Infections: An Update. Microorganisms. 2020;8(4). https://doi.org/10.3390/microorganisms8 040476.

2. Kourbeti IS, Tsiodras S, Boumpas DT. Spinal infections: evolving concepts. Curr Opin Rheumatol. 2008;20(4):471-9. https://doi.org/10.1097/BOR. 0b013e3282ff5e66 00002281-200807000-00017 [pii].

3. Tong YJ, Liu JH, Fan SW, Zhao FD. One-stage Debridement via Oblique Lateral Interbody Fusion Corridor Combined with Posterior Pedicle Screw Fixation in Treating Spontaneous Lumbar Infectious Spondylodiscitis: A Case Series. Orthop Surg. 2019;11(6):1109-19. https://doi.org/10.1111/os. 12562.

4. Solera J, Lozano E, Martinez-Alfaro E, Espinosa A, Castillejos ML, Abad L. Brucellar spondylitis: review of 35 cases and literature survey. Clin Infect Dis. 1999;29(6):1440-9. https://doi.org/10.1086/313524.

5. Valancius K, Hansen ES, Hoy K, Helmig P, Niedermann B, Bunger C. Failure modes in conservative and surgical management of infectious spondylodiscitis. Eur Spine J. 2013;22(8):1837-44. https://doi.org/10.1007/ s00586-012-2614-3.

6. Herren C, Jung N, Pishnamaz M, Breuninger M, Siewe J, Sobottke R. Spondylodiscitis: Diagnosis and Treatment Options. Dtsch Arztebl Int. 2017;114(51-52):875-82. https://doi.org/10.3238/arztebl.2017.0875.

7. Ozmen D, Ozkan N, Guberina N, et al. Computed-tomography-guided biopsy in suspected spondylodiscitis: Single-center experience including 201 biopsy procedures. Orthop Rev (Pavia). 2019;11(1):7793. https://doi. org/10.4081/or.2019.7793.

8. Gregori F, Grasso G, laiani G, Marotta N, Torregrossa F, Landi A. Treatment algorithm for spontaneous spinal infections: A review of the literature. J Craniovertebr Junction Spine. 2019;10(1):3-9. https://doi.org/10.4103/ jcvjs.JCVJS_115_18 JCVJS-10-3 [pii].

9. Homagk L, Marmelstein D, Homagk N, Hofmann GO. SponDT (Spondylodiscitis Diagnosis and Treatment): spondylodiscitis scoring system. J Orthop Surg Res. 2019;14(1):100. https://doi.org/10.1186/ s13018-019-1134-9.

10. Kamal AM, El-Sharkawi MM, El-Sabrout M, Hassan MG. Spondylodiscitis: experience of surgical management of complicated cases after failed antibiotic treatment. SICOT J. 2020;6:5. https://doi.org/10.1051/sicotj/ 2020002 sicotj190086 [pii].

11. Lee BH, Park JO, Kim HS, Lee HM, Cho BW, Moon SH. Transpedicular curettage and drainage versus combined anterior and posterior surgery in infectious spondylodiscitis. Indian J Orthop. 2014;48(1):74-80. https://doi. org/10.4103/0019-5413.125508 IJOrtho-48-74 [pii].

12. Rutges JP, Kempen DH, van Dijk M, Oner FC. Outcome of conservative and surgical treatment of pyogenic spondylodiscitis: a systematic literature review. Eur Spine J. 2016;25(4):983-99. https://doi.org/10.1007/ s00586-015-4318-y.

13. Vcelak J, Chomiak J, Toth L. Surgical treatment of lumbar spondylodiscitis: a comparison of two methods. Int Orthop. 2014;38(7):1425-34. https:// doi.org/10.1007/s00264-014-2360-8

14. Lin Y, Li F, Chen W, Zeng H, Chen A, Xiong W. Single-level lumbar pyogenic spondylodiscitis treated with mini-open anterior debridement and fusion in combination with posterior percutaneous fixation via a modified anterior lumbar interbody fusion approach. J Neurosurg Spine. 2015;23(6):747-53. https://doi.org/10.3171/2015.5.SPINE14876.

15. Si M, Yang ZP, Li ZF, Yang Q, Li JM. Anterior versus posterior fixation for the treatment of lumbar pyogenic vertebral osteomyelitis. Orthopedics. 2013;36(6):831-6. https://doi.org/10.3928/01477447-20130523-33.

16. Epstein NE. Incidence of Major Vascular Injuries with Extreme Lateral Interbody Fusion (XLIF). Surg Neurol Int. 2020;11:70. https://doi.org/10. 25259/SNI 1132020 SNI-11-70 [pii].

17. Li R, Li X, Zhou H, Jiang W. Development and Application of Oblique Lumbar Interbody Fusion. Orthop Surg. 2020;12(2):355-65. https://doi. org/10.1111/os.12625.
18. Yang SC, Chen WJ, Chen HS, Kao YH, Yu SW, Tu YK. Extended indications of percutaneous endoscopic lavage and drainage for the treatment of lumbar infectious spondylitis. Eur Spine J. 2014;23(4):846-53. https://doi. org/10.1007/s00586-013-3157-y.

19. Yang SC, Fu TS, Chen HS, Kao YH, Yu SW, Tu YK. Minimally invasive endoscopic treatment for lumbar infectious spondylitis: a retrospective study in a tertiary referral center. BMC Musculoskelet Disord. 2014;15:105. https://doi.org/10.1186/1471-2474-15-105.

20. Wang X, Zhou S, Bian Z, et al. Unilateral percutaneous endoscopic debridement and drainage for lumbar infectious spondylitis. J Orthop Surg Res. 2018;13(1):306. https://doi.org/10.1186/s13018-018-1009-5.

21. Xu DS, Walker CT, Godzik J, Turner JD, Smith W, Uribe JS. Minimally invasive anterior, lateral, and oblique lumbar interbody fusion: a literature review. Ann Transl Med. 2018;6(6):104. https://doi.org/10.21037/atm.2018. 03.24 atm-06-06-104 [pii].

22. Pee YH, Park JD, Choi YG, Lee SH. Anterior debridement and fusion followed by posterior pedicle screw fixation in pyogenic spondylodiscitis: autologous iliac bone strut versus cage. J Neurosurg Spine. 2008;8(5):405-12. https://doi.org/10.3171/SPI/2008/8/5/405.

23. Burkus JK, Foley K, Haid RW, LeHuec JC. Surgical Interbody Research Group--radiographic assessment of interbody fusion devices: fusion criteria for anterior lumbar interbody surgery. Neurosurg Focus. 2001;10(4):E11. https://doi.org/10.3171/foc.2001.10.4.12.

24. Liang XJ, Zhong W, Tang K, Quan Z, Luo XJ, Jiang DM. One-stage posterior debridement with transverse process strut as bone graft in the surgical treatment of single-segment thoracic tuberculosis: A retrospective single-center study. Medicine (Baltimore). 2019;98(47):e18022. https://doi. org/10.1097/MD.0000000000018022.

25. Taylor DG, Buchholz AL, Sure DR, et al. Presentation and Outcomes After Medical and Surgical Treatment Versus Medical Treatment Alone of Spontaneous Infectious Spondylodiscitis: A Systematic Literature Review and Meta-Analysis. Global Spine J. 2018;8(4 Suppl):49S-58S. https://doi. org/10.1177/2192568218799058.

26. Zarghooni $K$, Rollinghoff $M$, Sobottke R, Eysel P. Treatment of spondylodiscitis. Int Orthop. 2012;36(2):405-11. https://doi.org/10.1007/s00264-011-1425-1.

27. Sobottke R, Seifert H, Fatkenheuer G, Schmidt M, Gossmann A, Eysel P. Current diagnosis and treatment of spondylodiscitis. Dtsch Arztebl Int. 2008;105(10):181-7. https://doi.org/10.3238/arztebl.2008.0181.

28. Liu J, Feng H. Oblique Lateral Interbody Fusion (OLIF) with Supplemental Anterolateral Screw and Rod Instrumentation: A Preliminary Clinical Study. World Neurosurg 2020;134: e944-e950. doi: https://doi.org/10. 1016/j.wneu.2019.11.046. https://doi.org/S1878-8750(19)32882-7 [pii]

29. Mayer HM. A new microsurgical technique for minimally invasive anterior lumbar interbody fusion. Spine (Phila Pa 1976). 1997;22(6):691-9; discussion 700. https://doi.org/10.1097/00007632-199703150-00023.

30. Huo Y, Yang D, Ma L, Wang H, Ding W, Yang S. Oblique Lumbar Interbody Fusion with Stand-Alone Cages for the Treatment of Degenerative Lumbar Spondylolisthesis: A Retrospective Study with 1-Year Follow-Up. Pain Res Manag. 2020;2020:9016219. https://doi.org/10.1155/2020/9016219.

31. Ohtori S, Mannoji C, Orita S, et al. Mini-Open Anterior Retroperitoneal Lumbar Interbody Fusion: Oblique Lateral Interbody Fusion for Degenerated Lumbar Spinal Kyphoscoliosis. Asian Spine J. 2015;9(4):565-72. https://doi.org/10.4184/asj.2015.9.4.565.

32. Li HM, Zhang RJ, Shen CL. Differences in radiographic and clinical outcomes of oblique lateral interbody fusion and lateral lumbar interbody fusion for degenerative lumbar disease: a meta-analysis. BMC Musculoskelet Disord. 2019;20(1):582. https://doi.org/10.1186/s12891-019-2972-7.

33. Hah R, Kang HP. Lateral and Oblique Lumbar Interbody Fusion-Current Concepts and a Review of Recent Literature. Curr Rev Musculoskelet Med. 2019:305-10. https://doi.org/10.1007/s12178-019-09562-6.

34. Ha KY, Shin JH, Kim KW, Na KH. The fate of anterior autogenous bone graft after anterior radical surgery with or without posterior instrumentation in the treatment of pyogenic lumbar spondylodiscitis. Spine (Phila Pa 1976). 2007;32(17):1856-64. https://doi.org/10.1097/BRS.0b013e318108b804 00007632-200708010-00009 [pii].

35. Dai LY, Chen WH, Jiang LS. Anterior instrumentation for the treatment of pyogenic vertebral osteomyelitis of thoracic and lumbar spine. Eur Spine J. 2008;17(8):1027-34. https://doi.org/10.1007/s00586-008-0661-6.

36. Kuklo TR, Potter BK, Bell RS, Moquin RR, Rosner MK. Single-stage treatment of pyogenic spinal infection with titanium mesh cages. J Spinal 
Disord Tech. 2006;19(5):376-82. https://doi.org/10.1097/01.bsd.00002 03945.03922.f6 00024720-200607000-00015 [pii].

37. Schomacher M, Finger T, Koeppen D, et al. Application of titanium and polyetheretherketone cages in the treatment of pyogenic spondylodiscitis. Clin Neurol Neurosurg. 2014;127:65-70. https://doi.org/10.1016/j.cline uro.2014.09.027 S0303-8467(14)00389-8 [pii].

38. Xie T, Wang C, Yang Z, et al. Minimally Invasive Oblique Lateral Lumbar Interbody Fusion Combined with Anterolateral Screw Fixation for Lumbar
Degenerative Disc Disease. World Neurosurg. 2020;135:e671-8. https:// doi.org/10.1016/j.wneu.2019.12.105 https://doi.org/S1878-8750(19) 33137-7 [pii].

\section{Publisher's Note}

Springer Nature remains neutral with regard to jurisdictional claims in published maps and institutional affiliations.
Ready to submit your research? Choose BMC and benefit from:

- fast, convenient online submission

- thorough peer review by experienced researchers in your field

- rapid publication on acceptance

- support for research data, including large and complex data types

- gold Open Access which fosters wider collaboration and increased citations

- maximum visibility for your research: over $100 \mathrm{M}$ website views per year

At BMC, research is always in progress.

Learn more biomedcentral.com/submissions 